\title{
FRACTURE RESISTANCE AND FAILURE MODE OF TWO RESTORATION DESIGNS MADE OF MONOLITHIC HYBRID AND GLASS MACHINABLE CERAMICS ; IN VITRO STUDY
}

\author{
Carl Hany* $^{*}$ and Maha Taymour**
}

\begin{abstract}
Statement of the problem: Monolithic hybrid and glass ceramics are indicated for intracoronal and extracoronal ceramic restorations. Available data regarding selection of the appropriate ceramic type for each preparation design and its influence on fracture resistance of tooth restoration complex is still scarce.
\end{abstract}

Purpose: The purpose of this study was to evaluate in vitro the fracture resistance and investigate failure mode of two restoration designs (crowns and inlays) made from lithium disilicate glass ceramic and hybrid ceramic constructed by the CAD /CAM technique.

Materials and Methods: A total of twenty ceramic restorations restoring lower molars were designed and fabricated in this study. The restorations were divided into two groups; Group 1: Ten full coverage crowns and Group 2: Ten inlays. Each of the previous groups was further subdivided into two equal subgroups; Subgroup 1: Five restorations constructed from lithium disilicate glass ceramics (e.max CAD) and Subgroup 2: Five restorations constructed from hybrid ceramic (VITA ENAMIC) by the CAD/CAM technology. Two ivorine teeth were prepared following the guidelines for full coverage and inlay ceramic restorations, they were duplicated into stone dies followed by scanning, designing and milling of restorations. The stone dies were duplicated into epoxy dies where the restorations were adhesively cemented on them. All cemented samples were exposed to 2000 thermal cycles $\left(5^{\circ} \mathrm{C}\right.$ and $55^{\circ} \mathrm{C}$ in water) with a dwell time of 25 seconds in a computer controlled thermocycler. All specimens were loaded in a universal testing machine where fracture test was done by compressive mode of load applied occlusally using a metallic rod with round tip at cross-head speed of $1 \mathrm{~mm} / \mathrm{min}$ until fracture occurred. Fracture resistance values were recorded in Newtons then they were statistically evaluated and failure modes were analyzed.

Results: For group 1 representing crown restorations, a statistically significant difference was found between (e.max CAD) and (VITA ENAMIC) subgroups at $(\mathrm{p}=0.05)$ where the highest mean value of maximum load was found in (VITA ENAMIC) $(951.77 \mathrm{~N} \pm 81.05)$ and the lowest mean

\footnotetext{
* Associate Professor, Fixed Prosthodontics Department, Faculty of Oral and Dental Medicine. Cairo University.

** Lecturer, Fixed Prosthodontics Department, Faculty of Oral and Dental Medicine. Cairo University.
} 


\begin{abstract}
value of maximum load was found in (e.max CAD) (709.35 N土49.51). While for the second group representing inlay restorations, no statistically significant difference was found between (e.max $\mathrm{CAD})$ and (VITA ENAMIC) subgroups at $(\mathrm{p}=0.307)$ where the highest mean value of maximum load was found in (e.max CAD) $(627.71 \mathrm{~N} \pm 80.01)$ and the lowest mean value of maximum load was found in (VITA ENAMIC) (581.26 N \pm 51.74). For the e.max CAD subgroup, a statistically significant difference was found between (Crown) and (Inlay) groups at $(\mathrm{p}=0.005)$ where the highest mean value of maximum load was found in the crown group (790.35 N \pm 49.51$)$ and the lowest mean value of maximum load was found in the inlay group $(627.71 \mathrm{~N} \pm 80.01)$.Regarding the VITA ENAMIC subgroup, a statistically significant difference was found between (Crown) and (Inlay) groups at $(\mathrm{p}<0.001)$ where the highest mean value of maximum load was found in the crown group $(951.77 \mathrm{~N} \pm 81.05)$ and the lowest mean value of maximum load was found in the inlay group $(581.26 \mathrm{~N} \pm 51.74)$.
\end{abstract}

Conclusions: 1. All inlays and crowns constructed from hybrid and glass ceramics in this study revealed fracture load values falling in the range of physiologic masticatory forces 2 . When considering restoration of molars with full coverage crowns, VITA ENAMIC is more preferred than e.max CAD ceramic in terms of fracture resistance as it showed a higher statistical significant mean values.3. When planning to restore molars with minimally invasive intracoronal restorations, both ceramics can be used as there was insignificant statistical difference between them , however e.max CAD can be recommended due to its more favorable mode of fracture compared to VITA ENAMIC.4. Irrespective of preparation designs, both ceramics showed insignificant difference regarding fracture resistance mean values.

\section{INTRODUCTION}

Monolithic ceramic restorations are recommended to a greater extent over bilayered restorations, having the advantages of minimizing complex construction techniques.Besides issues associated with residual stresses at the core veneer interface and delamination of the veneer are eliminated in these single layered restorations ${ }^{(1-4)}$. Unfortunately, brittleness remains a drawback and main source of failure for several types of monolithic restorations as reported by previous studies ${ }^{(5-7)}$. These failures can be abrupt and can cause not only complete fracture of the bonded restoration but also it can extend to the underlying tooth structure in a pattern described as a catastrophic type. Lithium disilicate glass-ceramics and hybrid ceramics are common examples for these types of ceramics indicated for extra and intra-coronal restorations.

The e.max CAD glass ceramic was developed for CAD/CAM applications in 2006. The material is supplied in partially crystallized form enclosing metastable lithium disilicate crystals called the blue block. Once milled in the blue stage, it is then subjected to a crystalization process to reach its final microstructure. This thermal treatment transforms lithium metasilicate to lithium disilicate with matching tooth color. The resulting ceramic restoration attains a grain size of approximately $1.5 \mu \mathrm{m}$ and a crystal volume of $70 \%$ lithium disilicate incorporated in a glass matrix. This machinable glass ceramic reaches flexural strength of $360 \mathrm{MPa}{ }^{(8)}$.

A more recent approach to construct monolithic restorations is to use hybrid ceramics that were lately introduced to the dental market. These materials are not pure resins or pure ceramics. They possess the advantages of being cheaper, easier to mill and repair than pure ceramic blocks ${ }^{(9)}$. When compared to direct resin composite material, they showed improved mechanical and physical properties owing to their industrial polymerization under standardized high pressure and temperature, thus minimizing their shrinkage. This resulted in CAD/CAM blocks with reduced deficiencies and higher degree of conversion. ${ }^{(10)}$ VITA ENAMIC is an example of this 
type of hybrid blocks. It is composed of a sintered ceramic matrix filled with a polymer material. The percentage of the inorganic ceramic network is 86 $\mathrm{wt} \%$, while the organic polymer forms $14 \mathrm{wt} \%$. This mixture offers considerable advantages for the user. For instance, the susceptibility to brittle fracture is lowered than pure ceramics. Also excellent CAD/ CAM handling is achieved. ${ }^{(1)}$

Development and progress of adhesive dentistry helped to a great extent in the introduction of minimally invasive dentistry concept. Conservation of vital tooth structure is a critical factor for long term clinical prognosis of tooth restoration concept ${ }^{(12-14)}$. One of the minimal invasive concept applications are the intracoronal restorations. Whenever indicated, this restoration design offers several advantages over the full coverage restorations including ease in maintaining excellent periodontal health. Besides cementation can be done with less hydrolytic behavior, pulp's health and tooth's anatomical shape are preserved ${ }^{(15-17)}$. However, previous researches addressed the ceramic bulk fracture as the most common failure type for ceramic partial coverage restorations. ${ }^{(18,19)}$

Since fracture strength is considered one of the most important criteria for long-term clinical prognosis of fixed restorations ${ }^{(20)}$, thus several studies investigated the fracture strength of different ceramic systems, however, the reported results were highly variable ${ }^{(21-26)}$. In addition the number of studies recommending the best ceramic material used for different restoration designs in terms of fracture resistance are scarce. Thus, the purpose of this study was to evaluate in vitro the fracture resistance and investigate failure mode of two restoration designs (crowns and inlays) made from lithium disilicate glass ceramic and hybrid ceramic constructed by the CAD /CAM technique. The question here arises whether similar fracture values and patterns will appear in monolithic ceramics for intra and extracoronal restorations and, if so, which is considered to be the best material for each restoration design?
The null hypotheses of this study were as follows:

1. The restoration design would have no significant effect on the fracture resistance and failure mode of the two ceramic restorations.

2. Restorations made of hybrid ceramics would have a significantly lower fracture resistance values than those made of glass ceramics.

\section{MATERIALS AND METHODS}

A total of twenty ceramic restorations restoring lower molars were designed and fabricated in this study. The restorations were divided into two groups; Group 1:Ten full coverage crowns and Group 2: Ten inlays. Each of the previous groups was further subdivided into two equal subgroups ; Subgroup 1: Five restorations constructed from lithium disilicate glass ceramics (e.max CAD) and Subgroup 2: Five restorations constructed from hybrid ceramic (VITA ENAMIC) by the CAD/CAM technology.

\section{I) Dies construction:}

Two ivorine teeth were prepared following the guidelines for full coverage and inlay ceramic restorations : one tooth resembling mandibular second molar preparation for all-ceramic crown having the following criteria: $1.2 \mathrm{~mm}$ rounded shoulder finish line, $6 \mathrm{~mm}$ height on the buccal and lingual surfaces, $4 \mathrm{~mm}$ heigth on the proximal surfaces and with total occlusal convergence angle of 8 degrees..$^{(40)}$

The second ivorine tooth resembling a mandibular second molar preparation for all-ceramic occluso-mesial inlay having the following criteria: 8 degrees total occlusal divergence, occlusal portion of $6 \mathrm{~mm}$ mesiodistal length, $3 \mathrm{~mm}$ buccolingual width and $2.5 \mathrm{~mm}$ depth while the proximal box of the inlay preparation had dimensions of $4 \mathrm{~mm}$ height for the axial walls, $1.5 \mathrm{~mm}$ width and $2 \mathrm{~mm}$ height of the gingival seat ${ }^{(41)}$. Preparations were carried out by the aid of dental surveyor (NEY surveyor, Dentsply, New York, USA). 


\section{II) Fabrication of all ceramic restorations}

The ivorine dies were duplicated using rubber base impression material (Imprint 2, $3 \mathrm{M}$ ESPE, MN, USA) into dental stone (GC FujiRock: Type 4 dental stone, GC corporation, Tokyo, Japan) dies used for fabrication of the $\mathrm{CAD} / \mathrm{CAM}$ restorations.

\section{a) Fabrication of e.max restorations:}

Restorations were designed and milled with a CAD/CAM system "Cerec inLab" (Sirona dental, Bensheim, Germany) according to the manufacturer's instructions from lithium disilicate glass-ceramic blocks (IPS e.max CAD, Ivoclar Vivadent, Schaan, Liechtenstein). Extraoral scanner "inEos X5 scanner" (Sirona dental, Bensheim, Germany) was used to capture optical impressions of the stone dies. The software "Cerec Premium S.W 4.2.5" was then used to complete the designing process of the all ceramic crowns and inlays. Scanning and design were performed by the same clinician. Once this step was completed, the design was electronically sent to the milling unit "Cerec MCXL Premium" (Sirona dental, Bensheim, Germany). The milling parameters were set to $60 \mu \mathrm{m}$ for the spacer. Final crystallization of IPS e.max CAD restorations was performed after the milling procedure following the manufacturer's instruction with crystallization temperature of 840 ${ }^{\circ} \mathrm{C}$ and the dwell time was 7 minutes. Finally, the restorations were glazed by the use of IPS e.max Ceram Glaze Paste (Ivoclar Vivadent, Schaan, Liechtenstein) with a standard cooling procedure . The fit of the milled restorations was then checked on their corresponding dies.

\section{b) Fabrication of VITA ENAMIC restorations:}

The same procedures were followed for VITA ENAMIC restorations fabrication (VITA Zahnfabrik, Germany) except that they were neither crystallized nor glazed following their milling. The restorations were polished using the Vita Enamic clinical 2 step polishing Kit (VITA Zhanfabrik. Germany) using the prepolishing instruments for a standardized time of 60 seconds at a speed of $8,000 \mathrm{rpm}$, followed by the high-gloss polishing for another 60 seconds. All milled samples were then checked for proper fit on their corresponding dies.

\section{III) Duplication of the stone dies and adhesive cementation of the restorations: (e.max CAD and VITA ENAMIC)}

The stone dies were duplicated into twenty epoxy resin dies (Chemapoxy resin, CMB Chemicals, Egypt). The restorations were checked once more for proper fit on their corresponding expoxy resin dies. The intaglio surfaces of the e.max CAD restorations were etched with hydrofluoric acid (IPS Ceramic etching gel; Ivoclar-Vivadent, Schaan, Liestenstein) for 20 seconds, then rinsed under running water for 40 seconds and then dried for 30 seconds with oil free air. A silane-coupling agent (Monobond S; Ivoclar Vivadent) was applied and allowed to dry for 1 minute. The self adhesive system G-cem (G-C corporation, Tokyo, Japan) was used following manufacturer's instructions to cement the restorations to their corresponding dies. Restorations were seated and cemented under a constant load of $2 \mathrm{~kg}$ for 30 seconds using a customized cementing device, and excess luting material was removed. The light-polymerizing unit (Elipar LED curing unit, 3M ESPE) was held on the buccal, mesial, lingual, distal and occlusal surfaces for 40 seconds each. The curing power was 1200 $\mathrm{mW} / \mathrm{cm}^{2}$.

The exact same procedure was conducted for the VITA ENAMIC restorations with the exception that the hydrofloric acid etching time was 60 seconds.

\section{Thermocycling and fracture resistance testing:}

All cemented samples were exposed to 2000 thermal cycles $\left(5^{\circ} \mathrm{C}\right.$ and $55^{\circ} \mathrm{C}$ in water) with a dwell time of 25 seconds in a computer controlled thermocycler (Robota automated thermal cycle; BILGE, Turkey). This procedure was then followed by fracture resistance testing where the samples were individually mounted on a computer 
controlled materials testing machine (Model 3345; Instron Industrial Products, Norwood, MA, USA) with a load cell of $5 \mathrm{kN}$ and data were recorded using computer software (Instron ${ }^{\circledR}$ Bluehill Lite Software). Samples were secured to the lower fixed compartment of testing machine by tightening screws. Fracture test was done by compressive mode of load applied occlusally using a metallic rod with round tip ( $5 \mathrm{~mm}$ diameter) attached to the upper movable compartment of testing machine traveling at cross-head speed of $1 \mathrm{~mm} / \mathrm{min}$. with tin foil sheet in-between to achieve homogenous stress distribution and minimization of the transmission of local force peaks as shown in figure 1. The load at failure was manifested by an audible crack and confirmed by a sharp drop at load-deflection curve recorded using computer software (Bluehill Lite Software Instron ${ }^{\circledR}$ Instruments) The load required to fracture was recorded in Newton.

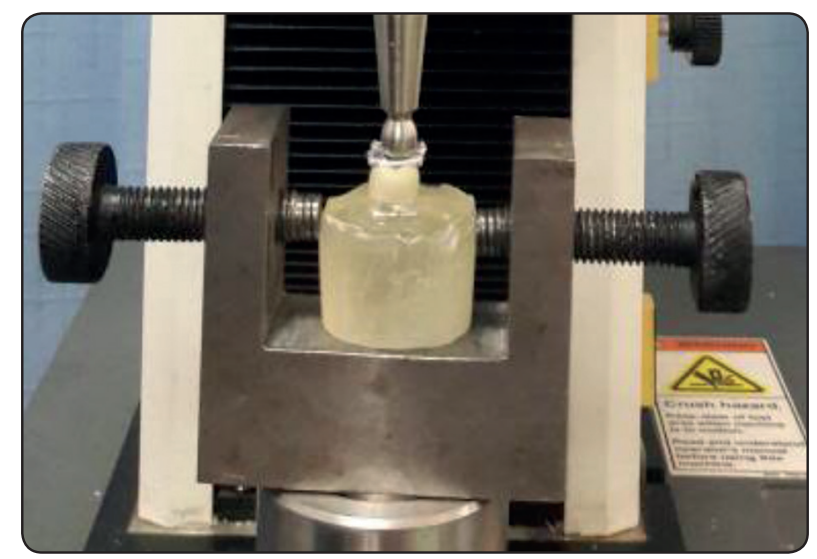

Fig. (1) : Mounted samples loaded in the universal testing machine for fracture resistance testing

The mode of failure was inspected visually and under an stereomicroscope (Leica, Germany) at magnification X12.5 and recorded for each fractured sample. Mode of failure was categorized according to the following criteria described by Burke ${ }^{(27)}$

Type I: Minimal fracture or crack in restoration.

Type II: Less than half of restoration is fractured.

Type III: Half of restoration is fractured .
Type IV: More than half of restoration is fractured.

Type V: Severe fracture of die.

\section{Statistical analysis:}

The mean and standard deviation values were calculated for each group and subgroup. Data were explored for normality using Kolmogorov-Smirnov and Shapiro-Wilk tests. Data showed normal distribution (Parametric). Independent sample t-test was used to compare between two groups in nonrelated samples. Two-way Analysis of Variance (ANOVA) was used in testing significance for the effect of both restoration design and ceramic materials on mean fracture resistance. The significance level was set at $\mathrm{P} \leq 0.05$. Statistical analysis was performed with $\quad$ IBM $®$ SPSS ${ }^{\circledR}$ Statistics Version 20 for Windows.

\section{RESULTS}

Data in table (1) shows the results of Two-way ANOVA analysis for the effect of different variables on mean fracture resistance. The results showed that restoration design had a statistically significant effect on mean fracture resistance at F-value 78.524 and P-value $<0.001$. Ceramic material has no statistically significant effect at F-value 3.651 and P-value 0.074. The interaction between the two variables had a statistically significant effect on mean fracture resistance at F-value 11.937 and P-value 0.003. Data in table 2 and figure 2 shows the mean, standard deviation (SD) values of fracture resistance (Newtons) in all groups and subgroups.

\section{- Effect of ceramic material within each restora- tion design:}

For group 1 representing crown restorations, a statistically significant difference was found between (e.max CAD) and (VITA ENAMIC) subgroups at $(p=0.005)$ where the highest mean value of maximum load was found in (VITA ENAMIC) (951.77 $\mathrm{N} \pm 81.05)$ and the lowest mean 
value of maximum load was found in (e.max CAD) $(709.35 \mathrm{~N} \pm 49.51)$.

While for the second group representing inlay restorations, no statistically significant difference was found between (e.max CAD) and (VITA ENAMIC) subgroups at $(p=0.307)$ where the highest mean value of maximum load was found in (e.max CAD) $(627.71 \mathrm{~N} \pm 80.01)$ and the lowest mean value of maximum load was found in (VITA ENAMIC) $(581.26 \mathrm{~N} \pm 51.74)$

\section{- Effect of restoration design within each ceramic material:}

For the e.max CAD subgroup, a statistically significant difference was found between (Crown) and (Inlay) groups at $(\mathrm{p}=0.005)$ where the highest mean value of maximum load was found in the crown group (790.35 $\mathrm{N} \pm 49.51)$ and the lowest mean value of maximum load was found in the inlay group $(627.71 \mathrm{~N} \pm 80.01)$

Regarding the VITA ENAMIC subgroup, a statistically significant difference was found between (Crown) and (Inlay) groups at $(p<0.001)$ where the highest mean value of maximum load was found in the crown group (951.77 $\mathrm{N} \pm 81.05)$ and the lowest mean value of maximum load was found in the inlay group $(581.26 \mathrm{~N} \pm 51.74)$

\section{- Effect of restoration design on fracture resis- tance regardless of ceramic material:}

A statistically significant difference was found between (Crown) and (Inlay) groups at $(p<0.001)$. The highest mean value of maximum load was found in Crown group (871.06 $\mathrm{N} \pm$ 106.05) and the lowest mean value of maximum load was found in Inlay group (604.49 $\mathrm{N} \pm 68.08)$

TABLE (1): Two-way ANOVA results for the effect of different variables on mean fracture resistance

\begin{tabular}{|c|c|c|c|c|c|}
\hline Source & Type III Sum of Squares & df & Mean Square & F & Sig. \\
\hline Design & 355305.822 & 1 & 355305.822 & 78.524 & $.000^{*}$ \\
\hline Material & 16520.327 & 1 & 16520.327 & 3.651 & $.074 \mathrm{~ns}$ \\
\hline Design x Material & 54012.421 & 1 & 54012.421 & 11.937 & $.003 *$ \\
\hline
\end{tabular}

$d f:$ degrees of freedom $=(n-1), *:$ Significant at $P \leq 0.05$

TABLE (2): The mean, standard deviation (SD) values of fracture resistance (Newtons) in all groups and subgroups

\begin{tabular}{|c|c|c|c|c|c|c|c|c|c|}
\hline \multirow{3}{*}{ Variables } & \multicolumn{9}{|c|}{ Fracture resistance (Newtons) } \\
\hline & \multicolumn{2}{|c|}{ e.max CAD } & \multicolumn{2}{|c|}{ 95\% CI } & \multicolumn{2}{|c|}{ VITA ENAMIC } & \multicolumn{2}{|c|}{ 95\% CI } & \multirow[t]{2}{*}{ p-value } \\
\hline & Mean & SD & Lower & Upper & Mean & SD & Lower & Upper & \\
\hline Crown & $790.35^{\text {aA }}$ & 49.51 & 728.87 & 851.83 & $951.77^{\text {ав }}$ & 81.05 & 851.13 & 1052.40 & $0.005 *$ \\
\hline Inlay & $627.71^{\mathrm{bA}}$ & 80.01 & 528.36 & 727.06 & $581.26^{\mathrm{bA}}$ & 51.74 & 517.02 & 645.50 & $0.307 n s$ \\
\hline p-value & \multicolumn{4}{|c|}{$0.005 *$} & \multicolumn{4}{|c|}{$<0.001 *$} & \\
\hline
\end{tabular}

Superscripts with different small letters indicate statistically significance difference within the same column. Superscripts

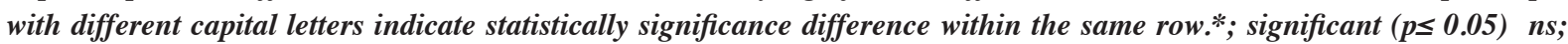
non-significant ( $p>0.05)$, 


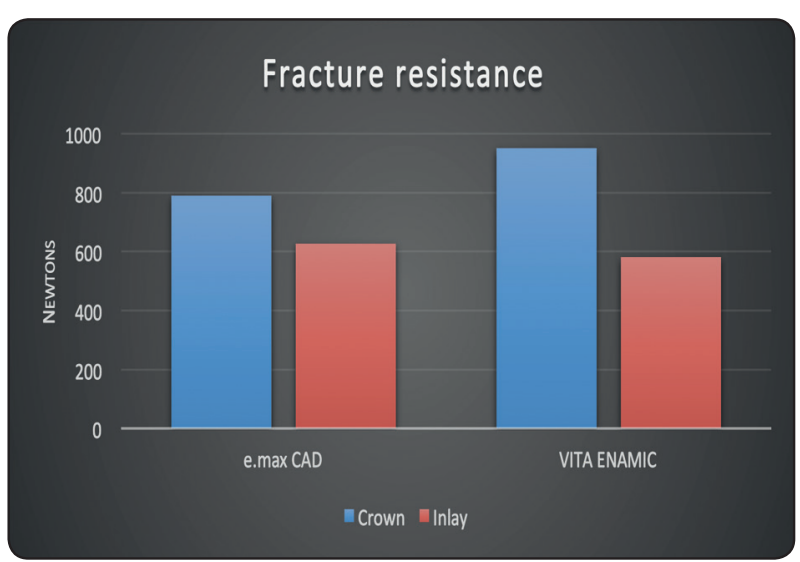

Fig. (2): Bar chart representing mean values of fracture resistance (Newtons) in all groups and subgroups

\section{- Effect of ceramic material on fracture resistance regardless of restoration design:}

No statistically significant difference was found between e.max CAD and VITA ENAMIC subgroups at $(p=0.442)$. The highest mean value of maximum load was found in VITA ENAMIC (766.51 N土
205.53) and the lowest mean value of maximum load was found in e.max CAD $(709.03 \mathrm{~N} \pm 106.22)$

Failure modes characteristics were defined and categorized by percentage according to Burke ${ }^{(9)}$ as shown in Table 3 and represented in Figure (3)

TABLE (3) Failure modes for the groups and subgroups (\%) under study:

\begin{tabular}{|c|c|c|c|c|c|c|}
\hline \multicolumn{2}{|c|}{} & \multicolumn{5}{|c|}{ Mode of failure \% } \\
\hline $\begin{array}{c}\text { Ceramic } \\
\text { type }\end{array}$ & $\begin{array}{c}\text { Restoration } \\
\text { design }\end{array}$ & I & II & III & IV & V \\
\hline \multirow{2}{*}{ e.max CAD } & Crown & 40 & 20 & 20 & 20 & 0 \\
\cline { 2 - 7 } & Inlay & 0 & 20 & 40 & 40 & 0 \\
\hline \multirow{2}{*}{$\begin{array}{c}\text { VITA } \\
\text { ENAMIC }\end{array}$} & Crown & 60 & 20 & 20 & 0 & 0 \\
\cline { 2 - 7 } & Inlay & 0 & 20 & 20 & 60 & 0 \\
\hline
\end{tabular}

I: Minimal fracture or crack in restoration. II: Less than half of restoration is fractured, III: Half of restoration is fractured, IV: More than half of restoration is fractured, V: Severe fracture of die

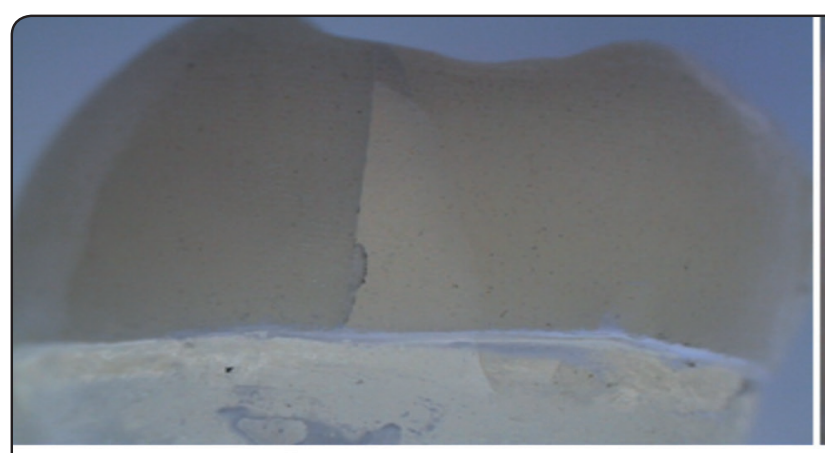

Crown

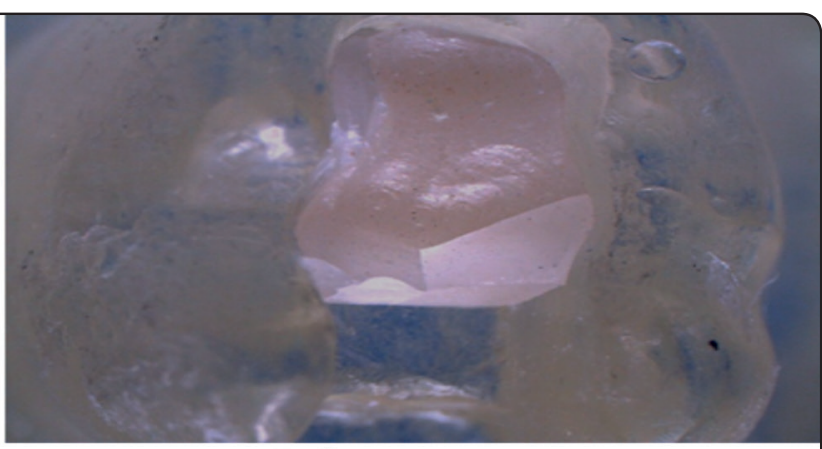

Inlay

e.max $C A D$

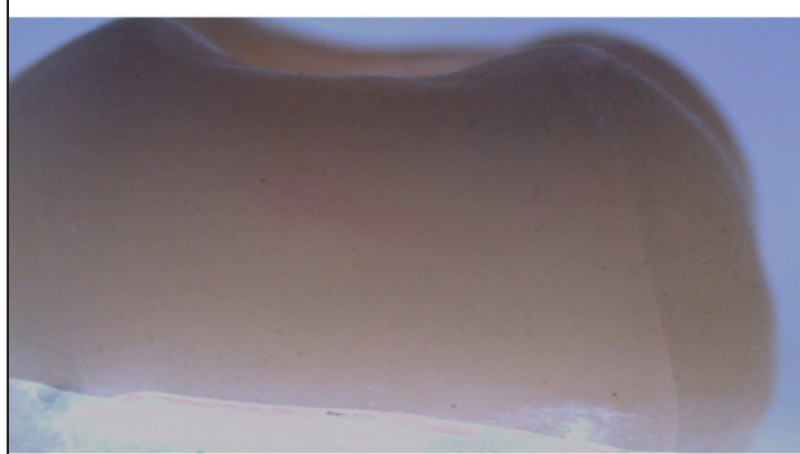

Crown

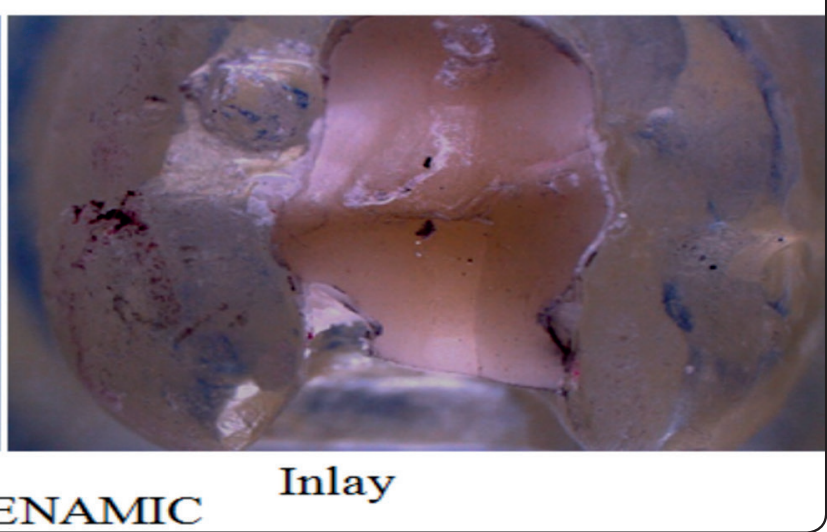

VITA ENAMIC

Fig. (3) Stereomicroscope images for fractured samples at magnification X12.5 


\section{DISCUSSION}

According to the results of this study, the first null hypothesis stating that restoration design would have no significant effect on the fracture resistance of the two ceramic restorations had to be rejected since the crown restorations group showed statistically significant higher mean fracture resistance values than the inlay restorations group. Also, the second null hypothesis stating that hybrid ceramic restorations would have a significantly lower fracture resistance values than those restorations made of glass ceramics was rejected as there was no significant difference between them in the inlay group while in the crown group, the glass ceramic restorations showed a significantly lower fracture resistance values than hybrid ceramic restorations.

Fracture resistance of all ceramic restorations is a prime factor for clinical longevity of fixed prostheses. ${ }^{(28)}$ Since ceramics are being known with their brittleness and low tensile strength properties, thus various techniques were introduced to run over this obstacle to allow their use safely in the posterior region. ${ }^{(21,29)}$ Adhesive bonding of ceramic restorations to the underlying tooth structure is one of the procedures that is adopted to increase the fracture resistance of both ; the prepared tooth and the restoration itself. ${ }^{25,31)}$ Fracture strength of the ceramic tooth complex depends on many factors related either to tooth as modulus of elasticity of the supporting substructure, tooth preparation design and surface roughness or related to the restoration as ceramic microstructure, mechanical properties and ceramic thickness or related to the adhesive interface as properties of the luting agent and residual stresses created in this layer as well as damage caused by occlusal function. ${ }^{(25,32-37)}$

Therefore, this in vitro study was conducted to assess the failure mechanism of two commonly used ceramic $\mathrm{CAD} / \mathrm{CAM}$ materials where the effect of the different preparation designs (crowns and inlays) can be selectively tested under highly standardized conditions.
Although using natural teeth during in vitro studies achieve more simulation to clinical conditions and better bonding than using dies, yet they usually have variable dimensions, structures and storage time after extraction causing difficulties in standardizing the abutments preparation. ${ }^{(38)}$ Accordingly, they were not used in this study, instead ivorine teeth were selected and prepared according to guidelines set for teeth preparation to receive full coverage and inlay restorations. ${ }^{(39-42)}$ This was made in an attempt to attain more homogenous results. The prepared ivorine teeth were then duplicated into stone dies in a trial to resemble the actual procedure done during construction of ceramic restorations.

The fracture resistance for all-ceramic restorations depends on modulus of elasticity of the chosen abutment material. ${ }^{(43)}$ Previous researches assessed the fracture strength of all ceramic restorations (21,44-56) using metal $^{(21,46,48,50)}$, brass, ${ }^{(44}$, ${ }^{51)}$ acrylic resin ${ }^{(45)}$, epoxy resin ${ }^{(49,52)}$, and dentin ${ }^{(47)}$ as die materials. They suggested that ideally the abutment material chosen for fracture resistance testing should react elastically as natural dentin does. ${ }^{(43)}$. In the present study, the load at fracture for the ceramic restorations was done after their adhesive cementation to epoxy resin dies due to their close resemblance to dentine in terms of modulus of elasticity. ${ }^{(43,57)}$.

Thermal cycling was performed in our study as a process representing laboratory simulation of the restoration clinical service. ${ }^{(58)}$

The number of cycles used was 2000 cycle equivalent to 1 year clinical service. ${ }^{(59)}$ The temperature range chosen was from $5^{\circ} \mathrm{C}$ to $55^{\circ} \mathrm{C}$ according to previous studies ${ }^{(60,61)}$ with a dwell time of 25 seconds as shorter time would not result in the desired thermal stress. ${ }^{(60)}$

Biting forces in the molar region were recorded in range of $597 \mathrm{~N}$ to $847 \mathrm{~N}$ for young women and men, respectively. ${ }^{(62)}$ Normal masticatory forces 
were reported to be from $37 \%$ to $40 \%$ of the biting force. ${ }^{(63,64)}$ In the present study the mean fracture resistance results ranged from $581.26 \mathrm{~N}$ to 951.77 $\mathrm{N}$ which is nearly within both the biting and anticipated masticatory force ranges. This indicates that mean fracture resistance values for all groups and subgroups used in our research falls in average range of masticatory forces.

When observing the results of the crown group, VITA ENAMIC showed a statistically significant higher fracture loads than e.max CAD crowns. This can be explained by the synergistic behaviour achieved between the polymer matrix of VITA ENAMIC, adhesive system and resin cement used having high resemblance in compositions leading to superb bonding capacity to the underlying substrate which in turn results in reinforcement of the restoration die complex and is finally reflected by increased fracture resistance values. (65) This explanation is based on previous studies reporting that the fracture resistance and fracture patterns of ceramic crowns are affected by ceramic microstructure and bond strength at the ceramic cement and tooth-cement interfaces. ${ }^{(66,67)}$ It may also be due to the fact that polymer phase of hybrid ceramics yield the crowns higher elastic properties compared to other ceramic crowns. ${ }^{(68)}$ Thus hybrid ceramics exhibit higher resiliency with more load absorption during the process of loading, hence, the fracture load is increased. ${ }^{(69)}$ This was in agreement with previous studies that reported similar findings ${ }^{(9,70-73)}$.

However, these results were in disagreement with Zhang et $\mathrm{al}^{(74)}$ who conducted their study on glass and hybrid ceramic crowns and found no significant difference between them in terms of fracture resistance. This inconsistency might be due to different restoration thicknesses, different bonding protocols and lack of thermocycling simulation in their study. Also the results were in confliction with other studies ${ }^{(75,76)}$ that evaluated flexural strength and fracture toughness of glass and hybrid ceramics and showed higher results for the glass ceramics, however, these studies were conducted on ceramic discs without bonding which might be the reason for inconsistency.

Although quantitative adhesive bond strength was not tested in the present study, yet it was observed that more VITA ENAMIC fragments still remained on the epoxy dies after fracture loading compared to e.max CAD fragments. Also when mode of fracture was inspected, e.max CAD crowns showed a higher percentage of debonding and fracture compared to VITA ENAMIC crowns. Again this indicates that increased bonding capacity can yield restorations having higher fracture resistance values.

This was not the case in the inlay group, where the e.max CAD ceramic had higher mean fracture load values than VITA ENAMIC ceramic. Although this difference was not significant yet it supports our previous explanation concerning the effect of bonding in increasing fracture resistance of polymer containing ceramic materials since the inlays had limited bonding area compared to full coverage crowns. (77) Besides the lower modulus of elasticity of VITA ENAMIC compared to e.max CAD, the hybrid restoration might not be able to conform to the loss of a proximal wall in large class 2 cavities and sustain occlusal loading that might be established on tooth restoration interface. These results were consistent with previous study that showed no significant difference between glass ceramic and PMMA based ceramic inlay restorations ${ }^{(78)}$ However, the results of inlay group disagreed with Soares et al. ${ }^{(65)}$, who reported a significant difference in fracture loads of ceramic and polymer based inlays with the later having higher values. This inconsistency in findings might be due to using different ceramic compositions and bonding protocols. It was also noticed from the fracture mode investigation that VITA ENAMIC inlays showed greater loss of the restoration following fracture test compared to e.max CAD in- 
lays, this gives a clue that increasing thickness and bonding area of the hybrid ceramics improves their fracture resistance due to their lower rigidity compared to glass ceramics ${ }^{(79,80)}$

Results regarding the effect of restoration design for both materials revealed that the crown restorations had statistically significant higher values compared to inlays. This may be referred to the fact that the full coverage restorations shows a more favorable stress distribution pattern mainly due to the increased bulk of material as well as increased bonding area . Also additional support can be gained from circumferential cervical margins of the crowns causing minimizing deflection during load application ${ }^{(81)}$

This study has some limitations. The fracture load applied to the restoration during testing was vertical and do not imitate clinical loading situation having vertical and lateral components due to limitations of loading device. Also resin dies were used instead of natural teeth for purpose of standardization. However, they are not identical to dentine in terms of microstructure, bonding mechanism and mechanical strength. Finally, clinical research is needed to determine the impact of more complex oral environmental conditions on mechanical properties of different ceramic restorations inspite of difficulty of standardization and controlling the variables

\section{CONCLUSIONS}

Within the limitations of this study, it was concluded that:

1. All inlays and crowns constructed from hybrid and glass ceramics in this study revealed fracture load values falling in the range of physiologic masticatory forces

2. When considering restoration of molars with full coverage crowns, VITA ENAMIC is more preferred than e.max CAD ceramic in terms of fracture resistance as it showed a higher statistical significant mean values.
3. When planning to restore molars with minimally invasive intracoronal restorations, both ceramics can be used as there was insignificant statistical difference between them, however, e.max CAD can be recommended due to its more favorable mode of fracture compared to VITA ENAMIC.

4. Irrespective of preparation designs, both ceramics showed insignificant difference regarding fracture resistance mean values.

\section{REFERENCES}

1. Christensen GJ: Porcelain-fused-to-metal vs non metal crowns. J Am Dent Assoc 1999;130:409-11

2. Zhang Y, Sailer I and Lawn BR: Fatigue of dental ceramics. J Dentistry 2013;41:1135-47.

3. Zhang Y, Lee JJ-W, Srikanth R and Lawn BR: Edge chipping and flexural resistance of monolithic ceramics. Dent Mater2013;29:1201

4. Christensen GJ. Is the rush to all-ceramic crowns justified J Am Dent Assoc 2014;145:192-4.

5. Fasbinder DJ, Dennison JB, Heys D and Nelva G: A clinical evaluation of chairside lithium disilicate cad/cam crowns: a two-year report. J Am Dent Assoc 2010;141:10S-4S.

6. Kern M, Sasse M and Wolfart S: Ten-year outcome of threeunit fixed dental prostheses made from monolithic lithium disilicate ceramic. J Am Dent Assoc 2012;143:234-40.

7. Reich S and Schierz O: Chair-side generated posterior lithiumdisilicate crowns after 4 years. Clin Oral Investig2013;17:1765-72.

8. IPS e.max CAD: Scientific documentation, Ivoclar Vivadent AG, Research and development Scientific Service, Schann, Leichtenstein, September, 2005.

9. El Zohairy A, De Gee A, Mohsen M. and Feilzer A: Microtensile bond strength testing of luting cements to prefabricated $\mathrm{CAD} / \mathrm{CAM}$ ceramic and composite blocks. Dent. Mater.2003 ;19:575-83

10. Keul, C, Muller-Hal M, Eichberger M, Leibermann A, Roos M, Edellhof D and Stawarczyk B:. Impact of different adhesives on work of adhesion between CAD/ CAM polymers and resin composite cements. J. Dent. 2014;42(9):1105-14

11. Vita.Vita Enamic ${ }^{\circledR}$ Technical and scientific documentation. 2013. 
12. Christensen GJ. Considering tooth-colored inlays and onlays versus crowns. J Am Dent Assoc 2008;139:617-20.

13. Zitzmann NU, Krastl G, Hecker H, Walter C and Weiger $\mathrm{R}$ : Endodontics or implants? A review of decisive criteria and guidelines for single tooth restorations and full arch reconstructions. Int Endod J 2009;42:757-74.

14. van Dijken JW and Hasselrot L: A prospective 15-year evaluation of extensive dentinenamel- bonded pressed ceramic coverages. Dent Mater 2010;26:929-39.

15. Van Dijken JW, Hasselrot L, Ormin A and Olofsson AL: Restorations with extensive dentine/enamel-bonded ceramic coverage: a 5-year follow up. Eur J oral Sci 2001; 8; 109: 222-229.

16. Burke FJ, Fleming GJ, Nathanson D and Marquis PM: Are adhesive technologies needed to support ceramics? An assessment of the current evidence. J Adhes Dent 2002; 4(1): 7-22.

17. Hickel $\mathrm{R}$ and Manhart J: Longevity of restorations in posterior teeth and reasons for failure. J Adhes Dent 2001; 3(1): 45-64.

18. Murgueitio R and Bernal G:Three-year clinical followup of posterior teeth restored with leucite-reinforced IPS empress onlays and partial veneer crowns. J Prosthodont 2012;21:340-5.

19. Naeselius K, Arnelund CF and Molin MK: Clinical evaluation of all-ceramic onlays: a 4-year retrospective study. Int J Prosthodont 2008;21:40-4.

20. Beschnidt SM and Strub JR :Evaluation of the marginal accuracy of different all-ceramic crown systems after simulation in the artificial mouth. J Oral Rehabil 1999; 26:582-593

21. AL-Makramani BM, Razak AA and Abu-Hassan MI: Evaluation of load at fracture of Procera AllCeram copings using different luting cements. J Prosthodont 2008 17:120-124

22. Riley EJ: Ceramo-metal restoration. State of the science. Dent Clin North Am 1977; 21:669-682

23. Josephson BA, Schulman A, Dunn ZA and Hurwitz W :A compressive strength study of complete ceramic crowns. Part II. J Prosthet Dent 1991; 65:388-391

24. Miller A, Long J, Miller B and Cole J :Comparison of the fracture strengths of ceramometal crowns versus several allceramic crowns. J Prosthet Dent 1992; 68:38-41
25. Yoshinari M and Dérand $\mathrm{T}$ :Fracture strength of all-ceramic crowns. Int J Prosthodont 1994; 7:329-338

26. Sobrinho LC, Cattell MJ and Knowles JC :Fracture strength of all-ceramic crowns. J Mater Sci Mater Med . 1998; 9:555-559

27. Burke FJ: Fracture resistance of teeth restored with dentinbonded crowns constructed in a leucite reinforced ceramic. Dent Mater 1999; 15:359-362.

28. Pröbster L and Diehl J :Slip-casting alumina ceramics for crown and bridge restorations. Quint Int 1992; 23:25-31

29. Harrington Z, McDonald A and Knowles $\mathrm{J}$ :An in vitro study to investigate the load at fracture of Procera AllCeram crowns with various thickness of occlusal veneer porcelain.2003; Int J Prosthodont 16:54-58

30. Burke FJ :The effect of variations in bonding procedure on fracture resistance of dentin-bonded all-ceramic crowns. Quintessence Int 1995;26:293-300

31. Pagniano RP, Seghi RR, Rosenstiel SF,Wang R and Katsube $\mathrm{N}$ :The effect of a layer of resin luting agent on the biaxial flexure strength of two all-ceramic systems. J Prosthet Dent 2005; 93:459-466

32. Scherrer SS and de Rijk WG: The fracture resistance of allceramic crowns on supporting structures with different elastic moduli. Int J Prosthodont 1993; 6:462-467

33. Rosenstiel SF, Land MF and Crispin BJ :Dental luting agents: a review of the current literature. J Prosthet Dent 1998; 80:280-301

34. Tsai YL, Petsche PE, Anusavice KJ and Yang MC. Influence of glass-ceramic thickness on Hertzian and bulk fracture mechanisms. Int J Prosthodont 1998;11:27-32

35. Campbell SD : A comparative strength study of metal ceramic and all-ceramic esthetic materials: modulus of rupture. J Prosthet Dent 1989;62:476-479

36. Sarafianou A and Kafandaris NM: Effect of convergence angle on retention of resin-bonded retainers cemented with resinous cements. J Prosthet Dent 1997;77:475-481

37. Cho L, Song H, Koak J and Heo S: Marginal accuracy and fracture strength of ceromer/fiber-reinforced composite crowns: effect of variations in preparation design. J Prosthet Dent 2002; 88:388- 395

38. Strub JR and Beschnidt SM: Fracture strength of 5 different allceramic crown systems. Int J Prosthodont 1998; 11: 602-609. 
39. Kílícarslan MA, Kedici SP, Kücükeşmen $\mathrm{CH}$ and Uludağ $\mathrm{CB}$ : In vitro fracture resistance of posterior metal-ceramic and all-ceramic inlay-retained resin-bonded fixed partial dentures. J Prosthet Dent 2004; 92:365-370.

40. McDonald A: Preparation guidelines for full and partial coverage ceramic restorations. Rest.dent. 2001; 28:84-90.

41. Thompson MC, Thompson KM and Swain M: The allceramic, inlay supported fixed partial denture. Part 1. Ceramic inlay preparation design: a literature review. Aust Dent J 2010; 55: 120- 127.

42. Beuer F, Steff B, Naumann M and Sorensen JA: Loadbearing capacity of all-ceramic three-unit fixed partial dentures with different computer-aided design (CAD)/ computer-aided manufacturing (CAM) fabricated framework materials. Eur J Oral Sci 2008; 116:381-386.

43. Yucel MT, Yondem I, Aykent F, Eraslan O: Influence of the supporting die structures on the fracture strength of all-ceramic materials. Clinical Oral Investigations 2012;16:1105-10.

44. Lee SK and Wilson PR : Fracture strength of all-ceramic crowns with varying core elastic moduli. Aust Dent J 2000; 45:103-107

45. Bindl A, Lüthy $\mathrm{H}$ and Mörmann WH : Strength and fracture pattern of monolithic CAD/CAM-generated posterior crowns. Dent Mater 2006; 22:29-36

46. Hwang JW and Yang JH: Fracture strength of copy-milled and conventional In-Ceram crowns. J Oral Rehabil 2001; 28:678-683

47. Preuss A, Rosentritt M, Frankenberger R, Beuer F and Naumann $\mathrm{M}$ : Influence of type of luting cement used with all-ceramic crowns on load capability of post-restored endodontically treated maxillary central incisors. Clin Oral Investig 2008; 12:151-156

48. Akesson J, Sundh A and Sjögren G : Fracture resistance of all ceramic crowns placed on a preparation with a sliceformed finishing line. J Oral Rehabil 2009;36:516-523

49. Wood KC, Berzins DW, Luo Q, Thompson GA, Toth JM and Nagy WW: Resistance to fracture of two all-ceramic crown materials following endodontic access. J Prosthet Dent 2006;95:33-41

50. AL-Makramani BM, Razak AA, and Abu-Hassan MI: Comparison of the load at fracture of Turkom-Cera to Procera All Ceram and In-Ceram all-ceramic restorations. J Prosthodont 2009; 18:484-488
51. Webber B, McDonald A and Knowles $\mathrm{J}$ : An in vitro study of the compressive load at fracture of Procera AllCeram crowns with varying thickness of veneer porcelain. J Prosthet Dent 2003;89:154-160

52. ZahranM, El-MowafyO, TamL,Watson PA and Finer Y: Fracture strength and fatigue resistance of all-ceramic molar crowns manufactured with CAD/CAM technology. J Prosthodont 2008;17:370-377

53. Sarafidou K, Stiesch M, Dittmer MP, Jörn D, Borchers L and Kohorst P: Load-bearing capacity of artificially aged zirconia fixed dental prostheses with heterogeneous abutment supports. Clin Oral Investig 2012; 16:961-968

54. Rosentritt M, Kolbeck C, Handel G, Schneider-Feyrer S and Behr M : Influence of the fabrication process on the in vitro performance of fixed dental prostheses with zirconia substructures. Clin Oral Investig 2011;15(6):1007-12.

55. Nothdurft FP, Merker S and Pospiech PR: Fracture behaviour of implant-implant- and implant-toothsupported all-ceramic fixed dental prostheses utilising zirconium dioxide implant abutments. Clin Oral Investig 2011; 15:89-97

56. Rosentritt M, Ries S, Kolbeck C, Westphal M, Richter EJ and Handel G : Fracture characteristics of anterior resinbonded zirconia-fixed partial dentures. Clin Oral Investig 2009; 13:453-457

57. Oh WS and Anusavice KJ: Effect of connector design on the fracture resistance of all-ceramic fixed partial dentures. J Prosthet Dent 2002; 87:536-542.

58. Galea M. and Darvellb B. :Thermal cycling procedures for laboratory testing of dental restorations. $\mathrm{J}$ of Dent 1999;27:89-99.

59. Yang R, Arola D, Han Z and Zhang X: A comparison of the fracture resistance of three machinable ceramics after thermal and mechanical fatigue .J Prosthet Dent 2014;112:878-885

60. Vasquez VZ, Ozcan M and Kimpara ET: Evaluation of interface characterization and adhesion of glass ceramics to commercially pure titanium and gold alloy after thermaland mechanical loading. Dent Mater 2009;25:221-31.

61. Vasquez V, Ozcan M, Nishioka R, Souza R, Mesquita A and Pavanelli $\mathrm{C}$ : Mechanical and thermal cycling effects on the flexural strength of glass ceramics fused to titanium. Dent Mater J 2008;27:7-15.

62. Waltimo A and Kononen M: A novel bite force recorder and maximal isometric bite force values for healthy young adults. Scand J Dent Res 1993; 101:171-5. 
63. Lundgren D and Laurell L: Occlusal force pattern during chewing and biting in dentitions restored with fixed bridges of cross-arch extension. I. Bilateral end abutments. J Oral Rehabil 1986; 13:57-71.

64. Gibbs CH, Mahan PE, Lundeen HC, Brehnan K, Walsh EK and Holbrook WB: Occlusal forces during chewing and swallowing as measured by sound transmission. $\mathrm{J}$ Prosthet Dent 1981; 46:443-9.

65. Soares CJ, Martins LR, Pfeifer JM and Giannini : Fracture resistance of teeth restored with indirect-composite and ceramic inlay systems. Quint Int 2004; 35(4): 281-6.

66. Chen HY, Hickel R, Setcos JC and Kunzelmann KH: Effects of surface finish and fatigue testing on the fracture strength of CAD-CAM and pressed-ceramic crowns. J Prosthet Dent 1999;82:468-75.

67. Kao EC and Johnston WM: Fracture incidence on debonding of orthodontic brackets from porcelain veneer laminates. J Prosthet Dent 1991;66:631-7.

68. Kunzelmann K, Jelen B, Mehl A, and Hickel R:Wear evaluation of mz100 compared to ceramic cad/cam materials. Int J of Comp Dent 2001; 4(3):171-184.

69. Attia A, Abdelaziz K, Freitag S and Kern M: Fracture load of composite resin and feldspathic all-ceramic CAD/CAM crowns. J Prosthet Dent 2006; 95(2):117-123.

70. Dalpino, C. E. Francischone, A. Ishikiriama and E. B. Franco: Fracture resistance of teeth directly and indirectly restored with composite resin and indirectly restored with ceramic materials. Am J of Dent 2002; 15(6):389-394.

71. Bremer B and Geurtsen W: Molar fracture resistance after adhesive restoration with ceramic inlays or resin-based composites. Am J of Dent 2001; 14(4):216-220.

72. Brunton P, Cattell F, Burke $\mathrm{J}$ and Wilson N: Fracture resistance of teeth restored with onlays of three contemporary tooth- colored resin-bonded restorative materials. J of Prosthet Dent 1999;82(2):167-171.
73. Shor A, Nicholls, J, Phillips K and Libman W: Fatigue load of teeth restored with bonded direct composite and indirect ceramic inlays in mod class ii cavity preparations. Int $\mathrm{J}$ of Prosth 2003; 16(1):64-69.

74. Zhang Y, Mai Z,Barani A, Bush M and Lawn B: Fractureresistant monolithic dental crowns Dent Mater 2016;32 : 442-449

75. Badawy R, Mowafy $\mathrm{O}$ and Tam L: Fracture toughness of chairside CAD/CAMmaterials - Alternative loading approach forcompact tension test Dent Mater 2016;32: $847-852$

76. Brian T, James K, Jukka P and Edmond H: Comparison of mechanical properties of three machinable ceramics with an experimental fluorophlogopite glass ceramic .J Prosthet Dent 2015;114:440-446.

77. Mörmann W \& Bindl A: The bonding area of intra- and extra-coronal tooth preparations. Am J Dent 2006;19:201205.

78. Ender A, Bienz S, Mörmanna W, Mehl A Attin T and Stawarczyk B: Marginal adaptation, fracture load andmacroscopic failure mode of adhesively lutedPMMAbased CAD/CAM inlays .Dent Mater 2016;3 2;22-29.

79. Magne P and Belser UC: Porcelain versus composite inlays/ inlays: Effects of mechanical loads on stress distribution, adhesion and crown flexure. Int J Periodontics Restorative Dent 2003; 23(6):543-55.

80. Magne $\mathrm{P}$ and Knezevic A: Thickness of CAD-CAM composite resin overlays influences fatigue resistance of endodontically treated premolars. Dent Mater 2009; 25:1264-8.

81. Thompson MC, Field CJ and Swain MV: The all-ceramic, inlay supported fixed partial denture. Part 2. Fixed partial denture design: a finite element analysis. Austral Dent J 2011; 56: 302-311. 